\title{
RESPONSABILIDADE DO ESTADO NA PROTEÇÃO E PREVENÇÃO DOS CRIMES DE TRÁFICO DE PESSOAS: A SITUAÇÃO EM MOÇAMBIQUE
}

\author{
Mário Jorge P. de C. Lima* \\ Armenio Alberto Rodrigues da Roda**
}

RESUMO: No presente artigo pretende-se explanar no âmbito jurídico e sócio-econômico o problema do tráfico de pessoas de Moçambique para outros países para fins de exploração sexual e trabalho forçado como violação de Dignidade Humana, e a questão da responsabilidade protetiva e preventiva a ser desempenhada pelo Estado na sua condição de agente ativo no controle e organização da sociedade, partindo do pressuposto de que a liberdade sexual e integridade física das pessoas são garantias fundamentais.

Palavras-chave: Tráfico de Pessoas; Exploração Sexual; Internacional; Dignidade Humana

\section{RESPONSIBILITY OF THE STATE IN THE PROTECTION AND PREVENTION OF CRIMES OF TRAFFICKING IN PERSONS: THE SITUATION IN MOZAMBIQUE}

\begin{abstract}
This article intends to explain in the juridical and socio-economic context the problem of the trafficking of persons from Mozambique to other countries for the purpose of sexual exploitation and forced labor as a violation of Human Dignity, and the question of the preventive and protective responsibility to be performed by the State in its condition of active agent in the control and organization of the society, assuming that the sexual freedom and physical integrity of the people are fundamental guarantees.
\end{abstract}

Keywords: Trafficking in Persons; Sexual Exploitation; International; Human Dignity

\section{INTRODUÇÃO}

Neste artigo pretende-se analisar o alcance jurídico da questão do tráfico de pessoas para fins de exploração sexual e trabalho forcado como violação da Dignidade da Pessoa Humana, sobretudo a partir da situação em Moçambique, mas não somente mediante análise jurídica, porque o tema apresenta também conteúdo sociológico de grande relevância para sua abordagem, a fim de compreender os fatores ou causas que levam a ocorrência dos tráficos de pessoas. 
Nesse objetivo, será necessário delimitar o papel do Estado na prevenção e repressão do atividades ilícitas, uma vez que a estrutura estatal consiste no mais elevado aparato orgânico da sociedade, com poderes para decidir em relação as vários assuntos que lhe são atribuídos pela Constituição, para exercer controle e organização de uma sociedade. Dentre várias atribuições e decisões que competem ao Estado através dos seus órgãos cabe-nos aludir ao seu papel ativo na proteção e prevenção dos crimes em geral, e em especial dos crimes de tráficos de pessoas, porque a atuação do Estado exerce função importante na imputação de responsabilidade criminal, quer nas investigações desencadeadas pelo Ministério Público, assim como em outras atividades preventivas de caráter educacional e de segurança.

No que tange a análise jurídica cabe recordar que a legislação de Moçambique e a doutrina em geral já tratam da questão de tráfico de pessoas, porem será necessário entender o tema, analisando o conceito de pessoa na perspectiva jurídica e perante o conceito da Dignidade Humana.

O tráfico de pessoas, especialmente de mulheres e crianças, não constitui nada novo. Historicamente, este se realizou sob diferentes formas, mas, no contexto da globalização, ess prática adquiriu novas e mais agressivas dimensões. Trata-se de fenómeno complexo, multifacetado que envolve interesse de múltiplas a nível institucional e comercial. Constitui uma atividade comercial a nível global, orientada pela procura, com um mercado enorme para mãode-obra barata e sexo comercial confrontado, muitas vezes, por quadros legislativos e políticas reguladoras insuficientes ou não experimentadas, e sem pessoal adequadamente treinado para enfrentá-lo.

O método a ser adotado na presente pesquisa de forma a alcançar o os objetivos pretendidos serão: método dedutivo baseada numa pesquisa bibliográfica e documental de forma a explicar o fenômeno.

\section{BREVE HISTÓRICO DO TRÁFICO DE MULHERES E CRIANÇAS EM MOÇAMBIQUE}

De início, lembramos que Moçambique é um país de origem e de trânsito para atividades de tráfico de pessoas. Existe também evidência de tráfico de pessoas a nível interno. O destino principal do tráfico moçambicano de pessoas é a África do Sul, a potência económica dessa região. No entanto, verifica-se aumento de escala do tráfico de pessoas de África para a Europa e para o médio oriente, sugerindo que os moçambicanos, tal como muitas outras nacionalidades africanas, também já participam desse negócio transnacional. 


\section{RESPONSABILIDADE DO ESTADO NA PROTEÇÃO E PREVENÇÃO DOS CRIMES DE TRÁFICO DE PESSOAS: A SITUAÇÃO EM MOÇAMBIQUE}

O presente fenômeno de tráfico de pessoas tem forte origem e ligações com o tráfico de escravos, vivido no passado remoto no continente africano onde milhares de mulheres africanas eram exploradas sexualmente de forma clandestina, embora essa realidade nunca tenha sido adequadamente denunciada e nem medidas foram tomadas para responsabilizar o perpetradores deste crime por causa do poder colonial dominante. $\mathrm{O}$ mesmo sucedia com as crianças que eram obrigadas a trabalhos forçados. Essas atividades continuam em proliferação até os dias atuais, porém pouco tem sido feito para a responsabilização dos operadores dessa pratica criminosa

Alguns estudiosos entendem que a partir do contato entre sujeitos muito diferentes surge o fator de conflito. O século XVI comprova historicamente o processo da escravidão e exploração do homem negro e outros povos de raças peculiares. Os contornos de proximidade física entre sujeitos sócio-economicamente desiguais também são indutores de situações análogas a exploração e escravidão. Por outro lado, o paradoxo desta perspectiva surge do fato empírico social, que considera a proximidade como fonte de capital social para os menos privilegiados, em oposição às situações socialmente mais perversas, como as de isolamento social. No entanto, o contato entre diferentes grupos sociais produz e cria novas formas e instrumentos mantenedores das relações de poder e de gênero.

A prevenção contra a exploração e escravidão de seres humanos implica renovar o comprometimento da relevância de abominar todas as formas de violência a direitos humanos e da liberdade, e recusar permitir impunidade penal a qualquer indivíduo envolvido nesses crimes, assim como a necessidade da efetivação das diretrizes da Carta dos Direitos Humanos da ONU. Na contemporaneidade, a exploração de seres humanos e a escravidão estão ligadas diretamente ao conceito de tráfico de pessoas.

De acordo com a ONU existe uma clara ligação da escravatura vivida em Moçambique com o aspecto atual de tráfico de pessoas com foco em mulheres e crianças que são pessoas vulneráveis, porém, no período colonial, muitas das mulheres eram exploradas sexualmente mas não podiam denunciar, e portanto mantinham silêncio, de forma a não colocar em perigo a sua vida.

No século XXI, os Estados sustentam uma conjuntura complexa, particularmente na condição de atores das Relações Internacionais. Isto significa que, na atualidade, os Estados interagem de forma complexa com atores não estatais que, em certos casos, apresentam poder susceptível de desafiar certas autoridades estatais, a exemplo das companhias multinacionais, 
as organizações não governamentais (ONGs), os movimentos terroristas, o crime organizado transnacional de tráfico de drogas e de pessoas, que operam numa dimensão sistêmica dominada pelo fenômeno da globalização e do paradigma neoliberal, que defende o Estado minimalista.

\section{RESPONSABILIDADE DOS ESTADOS QUANTO AO TRÁFICO DE PESSOAS NOS TRATADOS INTERNACIONAIS}

A Responsabilidade Internacional dos países para com atividades criminais de tráfico de pessoas através de fronteiras nacionais, na atualidade, se encontra estabelecida em complemento da Convenção das Nações Unidas contra o Crime Organizado Transnacional, a chamada Convenção de Palermo, concluída em 2000, que se aplica a atividades ilícitas de participação em organização criminosa, lavagem de dinheiro, corrupção e obstrução de justiça, quando realizadas com operações ou efeitos incidentes em mais de um país.

No que diz respeito ao tráfico de pessoas, o escopo da Convenção se estende por dois protocolos adicionais complementares que são Protocolo Adicional à Convenção das Nações Unidas contra o Crime Organizado Transnacional Relativo ao Tráfico de Migrantes por Via Terrestre, Marítima e Aérea, e o Protocolo Adicional à Convenção das Nações Unidas contra o Crime Organizado Transnacional Relativo à Prevenção, Repressão e Punição do Tráfico de Pessoas, em especial Mulheres e Crianças.

Os Protocolos Adicionais decorrem da evolução do tratamento normativo internacional da matéria do tráfico de pessoas que tem origem no Tratado de Paris entre Inglaterra e França em 1814, para repressão ao tráfico negreiro para fins de escravidão (Castilho, 2018), cujas disposições estão atualizadas na Convenção de Genebra de 1956, e depois se estende para a repressão do tráfico de mulheres brancas em convenções de 1904 e 1910, enfim substituídas pela Convenção da ONU de 1949, mais abrangente.

O Protocolo de Tráfico de Migrantes se aplica à prevenção e repressão a atividades de tráfico de migrantes, que consiste na promoção, mediante benefício material, de entrada ilegal de pessoas em território estrangeiro da qual as pessoas introduzidas não são nacionais nem residentes permanentes.

O Protocolo ao Tráfico de Pessoas se aplica à prevenção e repressão a atividades de tráfico de seres humanos, que consiste no recrutamento, transporte e destinação de pessoas para fins de exploração sexual, trabalho ou serviço forçado análogo à escravatura, ou para remoção de órgãos pessoas, promovido sobretudo mediante coação, uso de força, fraude ou abuso de autoridade. 


\section{RESPONSABILIDADE DO ESTADO NA PROTEÇÃO E PREVENÇÃO DOS CRIMES DE TRÁFICO DE PESSOAS: A SITUAÇÃO EM MOÇAMBIQUE}

A natureza sensível da matéria abordada pela convenção e protocolos, sobretudo porque patrocinados pela ONU e decorrentes de aperfeiçoamento histórico no sentido da civilização e humanismo, torna todos os países imputáveis em sentido amplo por eventual descumprimento de suas disposições, isto é, trata-se de obrigação erga omnes (Casella, 2008, p. 253), a ser respeitada por todos os estados para com a comunidade de nações, porque fundada em valores comuns.

Moçambique assinou essa Convenção e Protocolos em 2001 e os ratificou em 2006, assim como o Brasil, que assinou a Convenção e Protocolos em 2000 e os ratificou em 2004.

A adesão dos dois países à referida Convenção e Protocolos amplia a imputabilidade internacional dessas nações, porque transforma a matéria em obrigação decorrente de tratado plurilateral, ou seja, norma internacional objetiva e positivada, a ser observada pelos estados signatários, cujo descumprimento configura ilícito internacional indutor de eventual aplicação de sanções.

\section{O TRÁFICO DE PESSOAS COMO VIOLAÇÃO DA DIGNIDADE HUMANA}

O Protocolo Adicional à Convenção das Nações Unidas contra o Crime Organizado Transnacional relativo à Prevenção, Repressão e Punição do Tráfico de Pessoas, em especial Mulheres e Crianças, define o Tráfico de Pessoas (artigo $3^{\circ}$, a), como:

“ a) A expressão 'tráfico de pessoas' significa o recrutamento, o transporte, a transferência, o alojamento ou o acolhimento de pessoas, recorrendo à ameaça ou ao uso da força ou a outras formas de coação, ao rapto, à fraude, ao engano, ao abuso de autoridade ou à situação de vulnerabilidade ou à entrega ou aceitação de pagamentos ou benefícios para obter o consentimento de uma pessoa que tem autoridade sobre outra, para fins de exploração. A exploração incluirá, no mínimo, a exploração da prostituição de outrem ou outras formas de exploração sexual, o trabalho ou serviços forçados, escravatura ou práticas similares á escravatura, a servidão ou a remoção de órgãos;"

No Brasil, o I Plano Nacional contra Tráfico de Seres Humanos 2007-2010 considera o Protocolo Adicional em epígrafe, como o primeiro documento internacional com uma definição clara de tráfico para fins de exploração, e então diversas organizações internacionais têm trilhado novos horizontes no que diz respeito a uma abordagem mais integrada e eficaz no combate ao problema. Uma vez que o Brasil também sofre a atividade criminosa do tráfico de seres humanos, o plano nacional de combate ao tráfico de pessoas programado para o período 
2013 a 2016 prevê o incremento da cooperação internacional com os países vizinhos no combate a essa atividade.

Recorde-se que o tráfico de pessoas continua ocorrendo da mesma maneira, por isso uma definição teórica auxilia absorver novas percepções dos elementos que combinam a efetivação e progressão do fenômeno, que prossegue num processo de reconstrução e ressignificação em função a dinâmica da sociedade.

\subsection{Dignidade da Pessoa Humana}

O Min. Luís Roberto Barroso assinala uma concepção universal da Dignidade da pessoa Humana que merece um acolhimento, em que menciona três elementos mínimo que abarca o Dignidade Humana, que são: o valor intrínseco, autonomia e valor comunitário, sendo que o valor intrínseco concretiza a ideia não tratar uma pessoa como meio mas como fim em si mesmo, envolvendo vida a integridade física e psíquica, autonomia envolve a sua dimensão pública e privada referindo-se autogoverno do indivíduo como publica, correspondente nas deliberações democráticas ela abarca ainda o mínimo existencial que assegura o pressuposto os pressuposto para o exercício das liberdades e no que tange o valor comunitário não apresenta uma importância o estudo que se propõe que são a restrições individuais no caso de dano contra o terceiro.

Segundo Ingo Sarlet, quando aqui se fala em dimensões da dignidade da pessoa Humana, está-se a referir - num primeiro momento - à complexidade da própria pessoa Humana e do meio no qual desenvolve sua personalidade. Para além desta referência, tão elementar quanto relevante, o que se pretende apontar e sustentar, à luz de toda uma tradição reflexiva filosófica e jurídica, é que a noção de dignidade da pessoa humana (especialmente no âmbito do Direito), para que possa dar conta da heterogeneidade e da riqueza da vida, integra um conjunto de fundamentos e uma série de manifestações. Estas, ainda que diferenciadas entre si, guardam um elo comum pelo fato de comporem o núcleo essencial da compreensão do próprio conceito de dignidade da pessoa humana.

A dignidade da pessoa humana, antes mesmo de seu reconhecimento jurídico nas Declarações Internacionais de Direito e nas Constituições de diversos países, figura como um valor, que brota da própria experiência axiológica de cada cultura humana, submetida aos influxos do tempo e do espaço.

A proclamação da normatividade do princípio da dignidade da pessoa humana, na maioria das Declarações Internacionais e Constituições contemporâneas, conduziu ao 


\section{RESPONSABILIDADE DO ESTADO NA PROTEÇÃO E PREVENÇÃO DOS CRIMES DE TRÁFICO DE PESSOAS: A SITUAÇÃO EM MOÇAMBIQUE}

reconhecimento dos princípios como normas basilares de todo o sistema jurídico, afastando-se a concepção de programaticidade, que justificava a neutralização da eficácia dos valores e fins norteadores dos sistemas constitucionais.

No ordenamento jurídico brasileiro, o princípio constitucional da dignidade da pessoa humana se desdobra em inúmeros outros princípios e regras constitucionais, conformando um arcabouço de valores e finalidades a ser realizadas pelo Estado e pela sociedade civil, como forma de concretizar a multiplicidade de direitos fundamentais, expressos ou implícitos, da Carta Magna brasileira e, por conseguinte, da normatividade infraconstitucional derivada.

Pode-se afirmar que o princípio ético-jurídico da dignidade da pessoa humana importa o reconhecimento e tutela de um espaço de integridade físico-moral a ser assegurado a todas as pessoas por sua existência ontológica, relacionando-se tanto com a manutenção das condições materiais de subsistência quanto com a preservação dos valores espirituais de um indivíduo que sente, pensa e interage com o universo circundante (Soares, 2010)

Por sua vez, a intensa necessidade jurídica perceber o conceito de pessoa na qual a lei pretende proteger no que se refere ao tráfico de pessoas, doutrina brasileira oferece um amplitude no que tange os Direitos fundamentais e Direitos Humanos e entende pessoa como ser humano como fim dotado de razão e capaz de exercitar a sua autonomia (Sarmento, 2003), mas se trata de pessoa encarnada que também tem corpo e sentimentos e que experimenta necessidades materiais e psíquica e está enraizada numa cultura imersa em relações intersubjetivas que são essenciais para o desenvolvimento das suas necessidades, porem esta noção abarca três elemento essências que são : Valor intrínseco da pessoas, autonomia e mínimo existencial.

Apenas os primeiros dois elementos, $<$ o valor intrínseco e autonomia $>$ tem o relevo para as questões de tráficos de pessoas, porque na ocorrência de trafico para fins de exploração sexual e trabalho forçado coloca-se em risco a vida, a integridade física e liberdade de autodeterminação sexual que afeta o valor intrínseco e autonomia da pessoa.

O Código Civil Moçambicano define <pessoa> como toda pessoa aquele que teve um nascimento completo e com vida e que passar gozar de personalidade jurídica independente da capacidade jurídica

\subsection{O equívoco do argumento do consentimento da vítima na violação da própria}

\section{Dignidade Humana}


Não raro se verifica que existe consentimento da vítima na exploração sexual, e por isso especula-se se a vontade da vítima de permitir que ela seja explorada sexual não isentaria a violação da Dignidade da pessoa, uma vez que através deste meio ela garante a sobrevivência e satisfaz as suas necessidades, e portanto sua dignidade não estaria violada porque a pessoa tem a autonomia do seu corpo e sua liberdade garantidas.

Do mesmo modo, cabe entender que a exploração também pode ser feita em forma de um trabalho forçado em que as vítimas são remuneradas, ou sob outras formas de trabalho forçado nomeadamente servidão, como o trabalho fora de período normal de trabalho.

Este tem sido um dos problemas discutidos no âmbito do postulado da Dignidade Humana, porém o poder público através de legislações, atos e decisões judiciais têm interferido em esfera privada de forma a impedir algumas práticas que ofendem a dignidade humana, que estão em divergência com a vontade da vítima, em permitir ou colaborar que a sua exploração sexual ou laboral como meio de obter um rendimento para seu sustento.

Partindo do pressuposto que a Dignidade não pode ser vista apenas numa perspectiva subjetiva ao indivíduo ao concreto mas também o interesse coletivo a sensibilidade e moral coletiva que pode estar violado porem no < valor comunitário > apontado como um dos terceiros elementos da Dignidade da pessoa Humana que concede uma confere a dignidade uma dimensão heterônima ensejando restrições as liberdades individuais voltadas a proteção de Direitos de terceiros da Dignidade do próprio indivíduo e de valores partilhados na sociedade.

Esclarece Barroso que, quando se volta a proteção da pessoa contra si mesma, a tutela de valores moralmente compartilhados valor comunitário devem estar sob escrutínio permanente e estrito quanto ao moralismo afetar as escolhas pessoais.

Na situação em que a vítima se entrega a exploração sexual ou trabalho forçado deve ser considerada como presente a violação a Dignidade da Pessoa Humana contra o terceiro, em razão do valor moral partilhado pela comunidade, ou seja, nesta ordem de ideias, tais liberdades devem ser restringidas em razão do risco de violação da Dignidade coletiva moral.

Além disso, a exploração sexual quando decorrente de trafico ilícito contempla ainda, além da prostituição infantil, exposição de pessoas a atos pornográficos com menores ou com maiores, sexo forçado, estupro, violação sexual, uso de gráfica sexual, exibicionismo, voyeurismo, etc.

As diversas formas mencionadas violam o direito à integridade física e psíquica plasmado na Carta sobre tráficos de pessoas da ONU, bem como na Constituição de 


\section{RESPONSABILIDADE DO ESTADO NA PROTEÇÃO E PREVENÇÃO DOS CRIMES DE TRÁFICO DE PESSOAS: A SITUAÇÃO EM MOÇAMBIQUE}

Moçambique, e produzem a ocorrência do trauma de natureza física e psíquica de difícil tratamento, restando marcas nas pessoas por longo período.

\section{AS PRINCIPAIS CAUSAS DE TRAFICOS DE CRIANÇAS E MULHRES}

Antes da análise jurídica cabe abordar as questões de natureza sociológica que impulsionam a atividade de tráfico de pessoas (TP), a partir de documentos oficiais internos e externos, que são de grande importância para compreensão do problema,

\subsection{Fatores econômicos}

* Pobreza: Pobreza segundo o Banco Mundial (1995), a pobreza é uma condição caracterizada por uma severa privação das necessidades humanas básicas, incluindo alimentação, água potável, saneamento, saúde, habitação, educação e informação. Ela depende não somente da renda, mas também do acesso aos serviços. O relatório do Programa das Nações Unidas para o Desenvolvimento (PNUD), na sua edição 2013, coloca Moçambique no $185^{\circ}$ lugar na lista dos países com mais o baixo Índice do Desenvolvimento Humano (IDH). Nesta perspectiva, aliada a ruralização acentuada da economia nacional e ao analfabetismo, em conjunto com o fraco acesso a informação, a extrema pobreza acentua o problema do Tráfico de pessoas.

Um aspecto marcante decorre às desigualdades entre o campo e a cidade, o que incentiva constantemente o êxodo rural, com as populações campesinas a buscarem melhores condições de vida nas zonas urbanas. Este fluxo migratório contribui efetivamente para a satisfação das necessidades dos locais relativamente à melhoria da qualidade de vida. Entretanto, são vários os casos em que as populações são vítimas da atuação do crime organizado ligado ao tráfico de drogas e de seres humanos, sob falsas promessas de melhoria de condições de vida, emprego e educação nas grandes cidades (Relatório PGRM, 2014).

* Desemprego: O desemprego é outro grande desafio da economia Moçambicana e afeta cerca de $27 \%$ da população. A maioria da população em Moçambique vive na zona rural, onde os níveis de escolarização são baixos e as taxas de desemprego são altas, o crime organizado encontra nestas zonas "terreno fértil” para desenvolver as suas atividades criminosas, especialmente junto de pessoas que se encontram em grandes dificuldades financeiras. Por isso, do ponto de vista estratégico, o aliciamento das vítimas do TP está ligado às promessas de melhores condições de vida.

O processo de integração regional dos países da Comunidade de Desenvolvimento da África Austral (SADC) facilitou a circulação de pessoas e bens nos países da região, e então o crime organizado transnacional sofisticou os seus métodos de atuação, em termos de 
recrutamento e transporte das vítimas, que são depois exploradas nos países de destino, trazendo a caça furtiva, a imigração ilegal e o aumento do tráfico de pessoas (TP) como efeitos perversos da regionalização.

Ao nível do tráfico interno, o desemprego continua sendo uma das principais causas da existência de vítimas. Neste caso, as vítimas nem sempre são destinadas aos países vizinhos, havendo diversos casos de pessoas que saíram das suas zonas de origem na busca de um emprego nas cidades capitais do país.

O tráfico doméstico apresenta uma forte ligação com situação de exploração laboral “escrava”. O Chefe do Posto da Migração de Milange, informou que foi abortada tentativa de TP, quando um grupo de três crianças, vindas de Nampula, estavam escondidas em um caminhão, que tentou atravessar a fronteira. O suposto traficante alegou que estava a ajudar aos jovens a obter emprego (Relatório PGRM, 2014).

A aprovação da lei $n^{\circ}$ 6/2008, constitui um passo importante do Estado Moçambicano na busca de soluções para a prevenção e combate do TP. Entretanto, visitados vários pontos do país, fica claro que, embora importante pelo seu conteúdo, o Estado falha por não estar a difundi-la de modo satisfatório, especialmente entre as potenciais vítimas, populações das zonas rurais e das periferias das grandes cidades.

Os líderes comunitários, que convivem diretamente com as populações campesinas, os diretores das escolas, os gestores dos hospitais e centros de saúde, têm fraco domínio deste instrumento legal, o que concorre para uma maior deficiência na sua implementação. No caso, do Chefe da Localidade de Morrumbene Sede, por exemplo, afirmou nunca ter recebido nenhum tipo de informação em matérias ligadas ao TP.

Dada a complexidade do fenómeno do TP, torna-se imperativa implementação da estratégia interministerial que possibilitaria a tomada de medidas preventivas e sinérgicas para o combate a esta problemática (Relatório PGRM, 2014).

*Vulnerabilidade econômica: A extensão e escala global do tráfico de pessoas constituem a 'desvantagem da globalização. A globalização criou um mercado poderoso de procura de mãode-obra barata e pouco especializada em sectores como a agricultura, o processamento de alimentos, construção, serviços domésticos, manufatura com mão-de-obra intensiva, cuidados de saúde domiciliária, trabalho do sexo, o setor de serviços em geral, e o setor de entretenimento (circos, mendigar, jóquei em corridas de camelos). 


\section{RESPONSABILIDADE DO ESTADO NA PROTEÇÃO E PREVENÇÃO DOS CRIMES DE TRÁFICO DE PESSOAS: A SITUAÇÃO EM MOÇAMBIQUE}

Essas modalidades de procura existe tanto nos países industrializados como nos países em desenvolvimento. Os tipos de trabalho onde se utiliza a mão-de-obra traficada tendem a situar-se em setores onde é mais fácil manter condições de trabalho altamente exploradoras e que constituem enormes violações dos direitos humanos e das normas laborais, em locais e sob condições difíceis de serem monitoradas.

Nas regiões de origem em Moçambique, existem fortes fatores de pressão que compelem as populações a considerarem a emigração como uma opção. Os mecanismos legais para gerir a movimentação dos candidatos a migração podiam reduzir os incentivos para formas irregulares de movimentação de pessoas uma vez que o tráfico de pessoas é, em parte, o produto de uma governança imperfeita de migração (UNICEF, 2003).

*Corrupção nos setores público e privado de trabalho: Embora o estudo não tenha encontrado evidências de atos de corrupção, há relatos deste tipo de atos associados ao TP de acordo com os órgãos de comunicação social. Por exemplo, o caso das 27 crianças encontradas sem documentação em Ressano Garcia, que levanta dúvidas sobre o modo como as mesmas conseguiram se deslocar por mais de $200 \mathrm{~km}$ sem que tivessem sido detectados. Por outro lado, conforme reportaram as fontes, os chamados guias das travessias na fronteira cobram valores que variam entre os 100 e os 300 Rands (moeda da África do Sul) para atravessar viajantes sem passaporte ao longo da fronteira. Este fato suscita suspeitas sobre a idoneidade de alguns agentes da polícia, afetos aos postos fronteiriços nacionais.

\subsection{Fatores sociais}

*Práticas e crenças culturais discriminatórias: Em Moçambique os direitos das mulheres há muito que são violados e negados. Não obstante as disposições constitucionais que estipulam a igualdade formal entre os genêros a luz do artigo 35 da CRM, e as leis e políticas que declaram como ilegais as práticas tradicionais, estas continuam muitas vezes a ser valorizadas e toleradas, e são tipicamente ressuscitadas como forma de reafirmação da identidade ou devido ao fato das limitações sociais que as reprimiam deixarem de existir. Enquanto que as origens dessas práticas estão enraizadas em sistemas de crenças e de percepções de moralidade e de comportamentos em linha com as exigências sociais, muitas vezes ligados a necessidades de sobrevivência, a sua prática atual é muitas vezes prejudicial, particularmente para as meninas e mulheres (Policy Paper, 2006).

*Falta de conhecimento e informação: Enquanto que existe um aumento na conscientização internacional com relação ao problema de tráfico e os governos, incluindo o de Moçambique, 
juntamente com todo um conjunto de partes envolvidas e de interesse, estejam a providenciar informação, a organizar campanhas de publicidade e de formação, permanece baixo o nível de conscientização no seio da população. A crença comum de que "não pode acontecer a mim" continua forte não obstante a familiaridade local com o contrabando transfronteira.

As ofertas de emprego a jovens para colocar crianças em melhores circunstâncias são geralmente aceitas de acordo com o seu aspecto exterior. A familiarização com os recrutadores para tráfico de pessoas, que na realidade podem ser vizinhos ou familiares, reduz ainda mais o reconhecimento do risco do tráfico de pessoas.

Revela-se significativo efetuar pesquisa na área de ressurgimento e discernimento atual dessas práticas. O lobolo, uma característica da região sul de Moçambique, implica que o futuro marido paga uma soma de dinheiro, joalharia e roupas, ou como era feito antigamente, oferece cabeças de gado à noiva, pais e sua família em troca pela mulher. Um casamento resultante desta prática, permite aos homens escolherem uma cunhada mais nova para substituir a mulher, no caso desta não o satisfazer sexualmente.

O casamento precoce é uma característica normal das comunidades rurais, que constituem a maioria da população. Uma vez que muitas vezes é negado às jovens o acesso a educação nas comunidades rurais, estas são empurradas para o casamento logo que sejam consideradas “adultas”. A idade adulta é considerada como tendo sido alcançada na altura em que estas jovens são submetidas às cerimônias de iniciação ou quando iniciam a menstruação. As características demográficas do pós-conflito, como a escassez de homens, podem também contribuir para esta prática (Policy Paper, 2006).

*Acesso diferenciado à educação: A falta de acesso igual na formação escolar que limita as oportunidades das mulheres de aumentarem o seu rendimento através de melhores habilitações para atividades de especialização profissional e as conduz ao estado de vulnerabilidade.

A falta de formação escolar para as mulheres jovens e adolescentes em Moçambique tem contribuído significativamente para a questão de tráfico para fins de exploração sexual, visto que a falta de formação acadêmica não permite que as mulheres gozem mesma oportunidades e também contribui para falta de discernimento para tomadas decisões que as afaste do tráfico de pessoas (UNICEF, 20003).

*Políticas de migração com diferenciação de gêneros: As políticas e leis de emigração restritivas muitas vezes instituídas como medidas de “proteção”, mas que limitam a migração regular de mulheres, porque a maioria dos canais de migração oferece oportunidades em setores 


\section{RESPONSABILIDADE DO ESTADO NA PROTEÇÃO E PREVENÇÃO DOS CRIMES DE TRÁFICO DE PESSOAS: A SITUAÇÃO EM MOÇAMBIQUE}

predominantemente destinados aos homens (trabalho de construção e agricultura), além do menor acesso a informação sobre oportunidades de migração ou de trabalho, e quanto aos riscos da migração.

Historicamente os homens da região sul de Moçambique migravam. As mulheres eram marginalizadas e obrigadas a ficar nas áreas rurais, ocupadas com a reprodução e a mão-deobra comunitária com um aumento na carga de trabalho, enraizando dessa forma os valores patriarcais. Entretanto, devido ao aumento na mobilidade das populações, a falta de oportunidade em casa e melhores oportunidades de sustento em outros lugares, as mulheres estão cada vez mais a migrar.

A migração pode levar ao alargamento ou ampliação da autonomia das mulheres, contudo, em razão das políticas de migração mais favoráveis aos homens e o fato de que o recrutamento é feito por setores dominados pelos homens, as mulheres restam mais expostas à migração irregular e ao tráfico.

*Fronteiras facilmente penetráveis: A tradição de movimentação e migração para a África do Sul para fins comerciais e de trabalho, além do desconhecimento da natureza de atividades ilegais, a exemplo do contrabando de mercadorias, essencial à sobrevivência em tempos de guerra, contribuem para aceitação e antecipação de movimentações não reguladas.

O fato da existência de fronteiras facilmente penetráveis, juntamente com os distúrbios civis e políticos, além da falta de oportunidades econômicas, asseguram um fluxo constante, em direção a sul, tanto de migrantes legais como irregulares na África Austral, com possível cumplicidade de policiais e guardas fronteiriços com os traficantes, para deixar passar viajantes sem documentação regular (Molo, 2000).

\subsection{Destinação das vítimas do tráfico}

De acordo com o Relatório de 2003 sobre Migrações intitulado "Sedução, Venda e Escravatura: O Tráfico de Mulheres e Crianças para Exploração Sexual na África Austral” a exploração sexual e o trabalho forçado são os principais fins do tráfico de pessoas em Moçambique.

*Exploração sexual: Existem várias redes de tráfico de pessoas em operação mais ou menos em pequena escala que utilizam carrinhas táxi para passar clandestinamente tanto migrantes como mulheres pela fronteira.

Essas redes têm sua base em casas de trânsito estabelecidas na região fronteiriça entre Moçambique, Suazilândia e África do Sul, que operam através de uma rede de cúmplices em 
Johanesburgo, Maputo e na região do Lebombo onde recrutam, alojam e transferem mulheres. As frotas de carrinhas táxi viajam entre Maputo e Johanesburgo várias vezes por semana e transportam moçambicanos que visitam as famílias ou que procuram trabalho, e que utilizam os táxis como uma forma de transporte bem como de assistência para aqueles que atravessam a fronteira sem a necessária documentação.

As moças jovens intencionadas de encontrar trabalho na África do Sul ou que visitam familiares, mas findam como vítimas do tráfico de pessoas porque são recrutadas passivamente quando se aproximam dos postos de táxis. Aqui os agentes de tráfico selecionam as jovens que lhes podem trazer melhor preço de venda e persuadem-nas a utilizar os serviços do táxi (UNICEF, 2003). As vítimas são logradas sem suspeitar na partida, quando entram na África do Sul de forma irregular entre os seus companheiros de viagem, aparentemente como migrantes comuns que procuram trabalho. Uma vez no alojamento de trânsito, as vítimas são separadas dos companheiros de viagem, e então inicia o processo de isolamento, intimidação e exploração. Os traficantes moçambicanos estabelecidos em Maputo também recrutam jovens que trabalham no setor informal, nos mercados e comércio locais e que são usadas como trabalhadoras sexuais, não raro auxiliados por cúmplice, possivelmente conhecida da vítima, que oferecem às moças emprego como empregadas de restaurante ou domésticas na África do Sul. As trabalhadoras do sexo de Maputo são especificamente recrutadas para serem vendidas a casas de prostituição nas províncias de Gauteng e de KwaZulu-Natal.

Além de Maputo e das províncias do sul de Moçambique, a província de Nampula constitui outro centro principal de recrutamento de jovens para a indústria do sexo. A prostituição é comum, essencialmente como resultado da ocupação pré-independência por parte do exército português. As moças são também envolvidas em atividades sexuais numa idade muito jovem e a prostituição, tal como noutros lugares, torna-se uma estratégia de sobrevivência. Pouco se sabe sobre a forma como estas moças são recrutadas, ou se estão incluídas tanto aquelas já estabelecidas como trabalhadoras do sexo como as que não possuem qualquer experiência a este respeito. Suspeita-se também que moçambicanos do norte do país sejam traficados através do Zimbabwe para a África do Sul (UNICEF, 2003).

A exploração sexual incide sobre as vítimas do sexo feminino, devido ao seu elevado valor comercial. Isto tem a ver com o fato de as mulheres poderem realizar, diariamente, múltiplas relações sexuais, na perspectiva de maximização de lucros, com suspeita de uso de adolescentes e crianças nessa exploração sexual. 


\section{RESPONSABILIDADE DO ESTADO NA PROTEÇÃO E PREVENÇÃO DOS CRIMES DE TRÁFICO DE PESSOAS: A SITUAÇÃO EM MOÇAMBIQUE}

Entretanto, os resultados de investigações apontam que percentagem significativa de pessoas que não associam o tráfico de mulheres com os promotores da prostituição, pois os inquiridos estão eventualmente a revelar desconhecimento da realidade ou estão a esconder uma realidade, o que, em ambos casos, pode ser prejudicial para a eficiência e eficácia de qualquer ação de prevenção e combate ao TP (Tsireledzani, 2013).

A realidade empírica mostra que a exploração sexual ocorre em locais de entretenimento em Maputo, sobretudo nos bares de diversão noturna e bórdeis, que têm crescido em número e em qualidade ao nível dos centros urbanos, principalmente na África do Sul, como Cape Town, Durban, Johanesburgo e Port Elisabeth, que são cidades consideradas principais locais de “turismo sexual” usando pessoas traficadas de várias nacionalidades (Tsireledzani, 2013)

Recentemente também Angola de forma crescente vem ser citada como um dos locais de destino de mulheres traficadas para prestação de serviços sexuais personalizados ao domicílio, a exemplo do “caso Bento Cangamba” amplamente midiatizado pela comunicação social brasileira e portuguesa, que está sob investigação policial e judicial.

*Comércio de órgãos para transplantes: O tráfico de pessoas para a exploração sexual e trabalhos forçados consiste na vasta maioria dos incidentes, mas existe um aumento no tráfico de pessoas para órgãos humanos, ou extração de órgãos. Este tipo de atividade comercial tanto acontece a nível internacional, na sua maioria para a África do Sul, como também a nível interno.

A finalidade desse tráfico envolve duas razões distintas: em primeiro lugar, partes específicas do corpo humano como por exemplo os órgãos sexuais, coração, olhos e crânio que são usados em medicina tradicional, designada por 'muti'24 onde se crê que estes órgãos curam males e doenças desde impotência à SIDA e à infertilidade, e aumentam o poder e a riqueza (Molo, 2000). A outra finalidade é o comércio mais lucrativo a nível internacional do recolhimento de órgãos para transplantes (tipicamente os rins), que são armazenados em temperaturas frias e transportes por ar. Existem numerosos países de todos os continentes, incluindo entre outros a Europa, África e Ásia, que estão implicados neste complexo comércio de procura e oferta.

As facilidades de alojamento nas clínicas sul africanas de transplantes em hospitais privados têm a reputação de oferecer a mais alta qualidade, na medida que a diálise e as operações de transplante se tornam cada vez mais acessíveis na área do setor privado, consequências negativas causadas pela desigualdade social que podem permitir que aqueles 
com meios financeiros adquiram órgãos humanos à custa de pessoas pobres ou mesmo adquiram órgãos disponibilizados por essas pessoas por alguns dólares.

\section{ATUAÇÃO NECESSÁRIA DO ESTAdO NA PROTEÇÃO E PREVENÇÃO CONTRA O CRIME DO TRÁFICO DE PESSOAS}

O Estado representado pelos seus órgãos segundo o princípio da separação de poderes, nomeadamente legislativo, executivo e judiciário influi diretamente na ordem societária através dos poderes que lhe são atribuídos (Bobbio, 2012). O Estado como detentor do poder público interfere diretamente na esfera privada, com competência de deliberar sobre vários assuntos da sociedade, e no que tange a questão da criminalidade, através do seu ius imperi, o Estado emerge como o agente que tem a responsabilidade de investigar, julgar e punir a prática de crimes de tráficos de pessoas para fins de exploração sexual ou trabalhos forçados. A prática dessa atividade criminosa decresce quando o Estado atua através do judiciário atua de forma eficaz na investigação e responsabilização penal desse delito.

Em diversos países onde está instituído o estado de direito democrático a responsabilidade investigatória compete ao Ministério Público coadjuvado com a polícia nacional, ou seja, aplica-se como pressuposto que o poder investigatório se encontra vinculado direta e exclusivamente ao Estado, tanto na ação preventiva como repressiva.

Também cabe ao Estado a proteção dos direitos fundamentais e a promoção da justiça, ou seja, diante da notícia da prática de um ilícito penal faz surgir para o Estado o dever de apurar o fato por meio de seus órgãos institucionais legitimados, e de promover a ação penal correspondente, se for o caso, a fim de que seja proferida (pelo Estado-Juiz) uma decisão de mérito, condenando ou absolvendo o imputado. A esse conjunto de atividades dá-se o nome de persecução criminal.

A investigação como dever exclusivamente estatal deve ser realizada de forma eficaz no objetivo de trazer resultado positivo para a sociedade quanto à eventual prática de qualquer crime, inclusive quanto ao crime de tráfico de pessoas, devendo o Estado manter condições humanas e materiais para a responsabilização dos praticantes dessa atividade.

Cabe ressaltar que o Estado não pode usar apenas a atuação posterior à ocorrência dos fatos como modo de investigação, mas manter controle prévio através de todos sistemas policiais de modo a evitar o tráfico de pessoas de forma preventiva.

Além disso, cabe ao Estado realizar prestações positivas ou ações efetivas proteção e efetivação dos direitos fundamentais, uma vez que os órgãos estatais não são neutros perante 


\section{RESPONSABILIDADE DO ESTADO NA PROTEÇÃO E PREVENÇÃO DOS CRIMES DE TRÁFICO DE PESSOAS: A SITUAÇÃO EM MOÇAMBIQUE}

situações de risco dessa natureza, mas, ao contrário, consistem em aparelho institucional composto pelo legislativo, executivo e judiciário, sobretudo este último, como agente de inibidor e repressor desse tipo legal do crime.

Quanto à persecução judicial, cabe relembrar a função do Ministério Público na atividade investigatória, assim como na imputação criminal.

\section{CONCLUSÕES}

No que tange a questão de tráfico de pessoas para fins de exploração sexual, trabalhos forçados e mesmo extração de órgãos humanos, torna-se necessário compreender que não se trata apenas de um problema jurídico, mas que também subsiste composto de vários fatores sociais que concorrem para a atividade ilícita, cabendo instituir políticas de atuação estatal de repressão e prevenção. Portanto, há necessidade de intervenção de medidas jurídicas tanto quanto medidas sociais, e de outros setores que possam trabalhar de forma conjunta para impedir a prática do tráfico.

Há necessidade de reforçar o controle nas fronteiras principalmente no ponto de destino da vizinha África do Sul, cabendo ao governo realizar investimento tecnológico, policial, equipamentos e de tramitação de documentação migratória, de modo a manter controle que contribuirá decisivamente para a mitigação do tráfico de pessoas.

A melhoria do controle na saída e entrada de pessoas no país em todos os aspectos, partindo de provimento pelo governo de recursos humanos e materiais suficientes para evitar a movimentação de estrangeiros portadores de documentos falsos, alguns envolvidos no tráfico de tráfico humano, que reduzirá a fragilidade do controle no processo migratório.

Por outro lado, cabe adotar medidas jurídicas quanto a forma de investigação do Ministério Público assim como da polícia de investigação criminal, no que diz respeito a sua capacidade para investigar o crime organizado dessa natureza, que é um crime transnacional, e para isso os órgãos de investigação precisam de capacidade humana intelectual, bem como meios ou recursos tecnológicos que possibilitem investigação célere de forma a acautelar o bem jurídico colocado em causa. O Ministério Público e a polícia não podem investigar essa pratica apenas com papeis o computador, mas também com investimento em estudos do modo que alguns países evoluídos nessa matéria tratam da investigação, prevenção e repressão de crimes dessa natureza.

Não somente trabalhos jurídicos atendem essa questão mas também o trabalho nas comunidades junto com sociedade, escolas, professores, igrejas e outros agentes sociais de 
forma a sensibilizar as crianças e mulheres jovens da necessária cautela para com as formas de aliciamento e enganos no oferecimento de trabalho melhor ou estudo no exterior, para que a comunidade seja capaz de se auto-prevenir contra esses aliciamentos.

Como foi suscitado acima, umas das causas importantes de facilitação do aliciamento é a falta de acesso a educação das raparigas ou mulheres jovens, cabendo ao governo traçar medidas que estimulem o acesso das mulheres jovens à escola, o que contribuirá para a sua integração no mercado de trabalho e redução do analfabetismo, que aumenta a quantidade de vulneráveis e de vítimas.

Constatando-se que o tráfico de pessoas é um crime transnacional, que muitas das vezes envolve vários países, torna-se imprescindível a cooperação política, militar e policial internacional de forma a exercer um trabalho conjunto na esfera investigativa que trará eficácia na forma de combate e prevenção do tráfico de forma conjunta não isolada.

Portanto, o tráfico de pessoas como crime de natureza organizada e a transnacionalidade para fins de exploração sexual, trabalho forçado e extração de órgãos humanos merece um tratamento atencioso dos operadores do Direito, de forma a mitigar o fenômeno, em razão da magnitude do bem jurídico em alusão que tange a vida humana, a integridade física e autodeterminação sexual.

\section{REFERENCIAS BIBLIOGRÁFICAS}

BARROSO, Luís Roberto. A Dignidade da Pessoa Humana no Direito Constitucional Contemporâneo: natureza jurídica, conteúdos mínimos e critérios de aplicação. Versão provisória para debate público. WWW.luisrobertobarroso.com.br. Acesso em 21/02/2018

BOBBIO, Norberto. Estado, governo e sociedade: para uma teoria geral da política. Rio de Janeiro: Paz e Terra, 2012

CASELLA, Paulo Borba. Fundamentos do Direito Internacional Pós-Moderno. Ed. Quartier Latin. São Paulo, 2008.

CASTILHO, Ela Wiecko V. de. Trafico de pessoas: da Convenção de Genebra ao Protocolo de Palermo. < pfdc.pgr.mpf.mp.br> acesso em 21/02/2018

MOCAMBIQUE. Lei de Base de Proteção da Criança, Lei da Organização Jurisdicional de Menores e Lei Sobre o Tráfico de Pessoas. Maputo: Central Impressora e Editora de Maputo, 2008.

MOLO Songololo The Trafficking of Children for Purposes of Sexual Exploitation in South Africa, 2000. 


\section{RESPONSABILIDADE DO ESTADO NA PROTEÇÃO E PREVENÇÃO DOS CRIMES DE TRÁFICO DE PESSOAS: A SITUAÇÃO EM MOÇAMBIQUE}

POLICY PAPER, Trafico de pessoas em Moçambique, 2006.

RELATÓRIO da Procuradoria Geral da República de Moçambique (PGRM), Estudo sobre o Tráfico de pessoas, Maputo, 2014.

SARLET, Ingo. Proibição de retrocesso, Dignidade da pessoa humana e Direitos sociais: manifestação de um constitucionalismo dirigente possível. In Constituição e Democracia: estudos em homenagem ao Prof. JJ Gomes Canotilho. Coord. Paulo Bonavides, Francisco Gerson Marques de Lima, Fayga Silveira Bedê, p. 291 a 335.São Paulo: Malheiros, 2006.

SARMENTO, Daniel. Os Princípios Constitucionais da Liberdade e da Autonomia Privada. In Dos princípios constitucionais: considerações em torno das normas principiológicas da Constituição Org. George Salomão Leite. São Paulo: Malheiros, 2003.

SOARES, Ricardo Maurício Freire. O princípio constitucional da dignidade da pessoa humana. São Paulo: Saraiva, 2010.

TSIRELEDZANI: Understanding the Dimensions of Human Trafficking in Southern África NATIONAL PROSECUTING OF SOUTH AFRICA, 2010.

UNICEF, Trafficking in Human Beings, Especially Women and Children, in Africa, Innocenti Research Centre. 2003. 